\title{
Position reversal learning as affected by occipital, posterior thalamic, and rubral lesions in the white rat $^{1}$
}

\section{B. MICHAEL THORNE and ROBERT THOMPSON, Louisiana State University, Baton Rouge, La. 70803}

Albino rats with bilateral lesions, involving the occipital cortex, nucleus posterior thalami, or red nucleus, and sham-operated controls were trained on a series of position-reversal problems. All brain-damaged animals performed more poorly than the controls, and the occipitalectomized animals were inferior to the other operated groups. These results fail to support the notion that damage to the occipital cortex, posterior diencephalon, or ventral mesencephalon produce visual discrimination retention deficits by heightening responsiveness to spatial cues.

Several lesion studies dealing with the performance of visual discrimination tasks in the white rat (Thompson \& Massopust, 1960; Thompson, 1963, 1969) have disclosed that only three general areas of the brain are crucial for normal retention. These areas, which presumably make up the core of a "visual memory system," include the occipital cortex, posterior diencephalon, and ventromedial mesencephalon.

One possible explanation for the observed deficits in visual discrimination performance arising from these lesions is that the animal's responsiveness to spatial cues is markedly enhanced and, as a consequence, interferes with the execution of previously learned approach-avoidance response patterns associated with the visual discriminanda. Consistent with this possibility is the finding that during the presolution period of the retention test for $v$ isual discrimination habits, occipitalectomized animals are apt to show strong position preferences, and animals with posterior thalamic or rubral lesions tend to display a strong perseverance tendency (Thompson, 1969).

To test the possibility of enhanced responsiveness to spatial cues, rats with either occipital, posterior thalamic, or red nucleus lesions were trained on a series of reversals of a position habit. If, indeed, the lesions heighten responsiveness to spatial cues, the brain-damaged animals should perform either better than, or at least as well as, the controls.

\section{METHOD}

The Ss were adult male albino rats of the Wistar strain. Two weeks prior to the onset of training, the animals sustained bilateral occipitalectomies (Group VC), bilateral nucleus posterior thalamic lesions (Group NP), bilateral red nucleus damage (Group RN), or sham operations (Group SO). Occipitalectomies were performed by means of aspiration, while the subcortical lesions were produced by the usual stereotaxic technique.

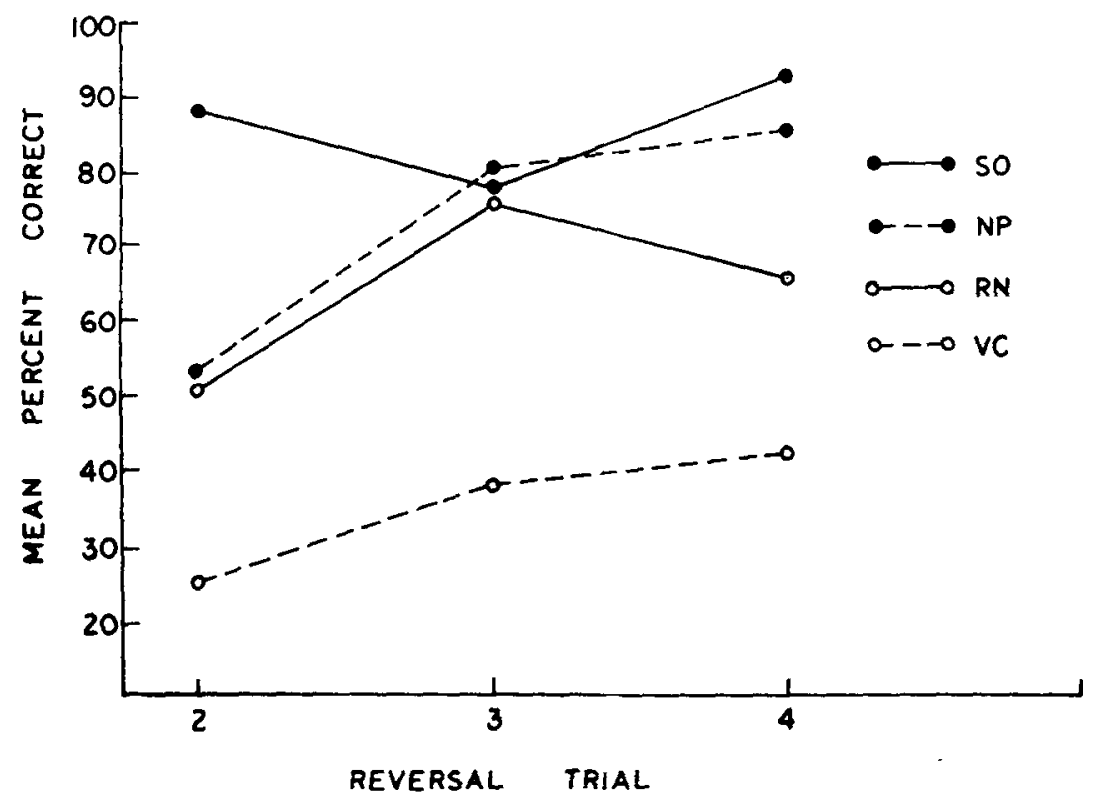

The apparatus consisted of a two-choice discrimination box utilizing escape from footshock as a motive (Thompson \& Bryant, 1955). A "blind" control procedure was used in training so that neither $E$ was aware of the group from which the animal came. Reversal learning was begun following 2 days of preliminary training, in which the animals were "shaped" to run from the startbox, through the choice chamber, push aside a white card placed against the window, and enter the goalbox. Two reversal problems were given each day within one session of eight trials. The intertrial interval was held constant at $60 \mathrm{sec}$. On Trials 1 through 4, the nonpreferred side (as revealed by performance during preliminary training) was correct, whereas on Trials 5 through 8 , the originally preferred side became correct. A response to the unlocked card on the correct side admitted the animal to the goalbox, but a response to the locked card on the incorrect side (error) was punished by mild shock to the feet. Correction for errors was allowed.

In some instances, a correct response was made on either Trial 1 or Trial 5 (first reversal trial). While the usual three trials were given following this event, the animal was considered not to have completed a reversal problem. Training was continued daily until the animal completed a total of eight reversal problems beyond the second day of reversal learning. All statistical analyses concentrated on performance during these eight reversal problems.

At the conclusion of the experiment, histological verification of lesion placernents was made.

\section{RESULTS}

Due to inaccuracies in lesion placements, five animals were discarded from the experiment. An additional four animals (two from Group SO and two from Group RN) were discarded because of a rigid position habit that persisted throughout the first 5 days of reversal training. This left for analysis five rats in Group SO, five in Group NP, five in Group RN, and three in Group VC.

Figure 1 depicts the performance of all groups on Trials 2,3, and 4 over the last eight reversal problems. A nonparametric analysis of variance test, comparing the various groups with respect to total per cent correct responses, was found to be significant $(\mathrm{p}<.01)$. Individual comparisons revealed that all three brain-damaged groups performed more poorly than did Group SO. Group VC was significantly worse than Group NP, and the comparison between Group VC and

Fig. 1. Mean performance of all groups on the last eight reversal problems. 
Group RN approached statistical significance $(p=.07)$. Groups $N P$ and $R N$ did not differ significantly.

When group comparisons were made with respect to performance on each of the three reversal trials, Group SO was found to be superior to the other three groups on Reversal Trial 2, superior to Group VC on Reversal Trial 3, and superior to Groups $V C$ and RN on Reversal Trial 4. Group VC performed more poorly than did Group NP on all three reversal trials and was significantly different from Group RN on Reversal Trial 2. Groups NP and RN again did not differ significantly on any reversal trial.

Comparisons of performance within each group on the first four reversal problems vs the last four reversal problems failed to reveal any evidence for a change in response accuracy over the course of training.

The subcortical lesions suffered by Groups NP and RN failed to destroy more than $50 \%$ of the nucleus posterior thalami and red nucleus, respectively. However, on the basis of earlier records (Thompson, 1969; Thorne, 1969), 50\% destruction of either subcortical nucleus would be sufficient to produce significant relearning deficits of brightness- and pattern-discrimination habits. All three animals of Group VC sustained virtually complete bilateral removals of the posterior one-half of the neocortical surface.

\section{DISCUSSION}

It is clear that the brain-damaged rats of the present study were markedly inferior to the sham-operated controls on the repeated reversal of a position habit. However, all brain-damaged groups were not equally deficient. Group VC was significantly poorer than Group NP on practically every measure of performance and probably would have been significantly worse than Group RN if more animals had been involved. Such intergroup comparisons, however, cannot be taken too seriously. First of all, none of the animals in Groups NP and RN sustained complete bilateral damage to the nucleus posterior and red nucleus, respectively. In the second place, the lesions of Group VC were on the order of $50 \%$ damage to the total neocortical surface, destroying not only the occipital areas but the parietal and insular-temporal areas as well. It is conceivable that damage to the latter areas is responsible for the severe deficit in reversal performance in Group VC (see Kaada, Rasmussen, \& Kveim, 1962).

In any event, the overall results do not support the hypothesis stated at the outset of this paper that occipital, posterior diencephalic, or ventral mesencephalic lesions interfere with retention of visual discrimination tasks due to a heightened tendency to respond to spatial cues. REFERENCES

KAADA, B. R., RASMUSSEN, E. W., \& KVEIM, $O$. Impaired acquisition of passive avoidance behavior by subcallosal, septal, hypothalamic, and insular lesions in rats. Jewrnal of Comparative \& Physiological Psychology, 1962, 55, 661-670.

THOMPSON, R. Cortical and subcortical structures mediating visual discrimination habits in the rat. Boletin del Instituto de estudios Medicos y biologicos, Universidad nacional de Mexico, 1963, 21, 451-466.

THOMPSON, R. Localization of the "visual memory system" in the white rat. Journal of Comparative \& Physiological Psychology, Monograph Supplement, 1969, in press.

THOMPSON, R,, \& BRYANT, J. H. Memory as affected by activity of the relevant receptor. Psychological Reports, 1955, 1, 393-400.

THOMPSON, R., \& MASSOPUST, L. C. The effect of subcortical lesions on retention of a brightness discrimination in rats. Journal of Comparative \& Physiological Psychology, $1960,53,488-496$.

THORNE, B. M. Visual discrimination performance in rats following nucleus posterior thalami and di-mesencephalic juncture damage. Unpublished doctoral dissertation, Louisiana State University, 1969. NOTE

1. This research was supported in part by USPHS Grant MH 08377 and in part by a NASA traineeship held by B. M. Thorne. 